American Journal of Microbiology 2 (2): 35-39, 2011

ISSN 1948-982x

C 2011 Science Publications

\title{
Strains of Klebsiella Pneumoniae from Intensive Care Unit Producing CTX-M-15 Extended Spectrum Beta Lactamases
}

\author{
${ }^{1}$ Iroha, I.R., ${ }^{1}$ A.E. Oji, ${ }^{2}$ A.E. Nwakaeze, \\ ${ }^{3}$ T.E. Ayogu, ${ }^{1}$ F.N. Afiukwa, ${ }^{2}$ P.C. Ejikeugwu and ${ }^{2}$ C.O. Esimone \\ ${ }^{1}$ Department of Applied Microbiology, \\ Ebonyi State University, P.M.B. 053, Abakaliki, Nigeria \\ ${ }^{2}$ Department of Pharmaceutical Microbiology and Biotechnology, \\ Nnamdi Azikiwe University, P.M.B. 5025 Awka, Nigeria \\ ${ }^{3}$ Department of Food Science and Technology, School of Technology, \\ Institute of Management and Technology, P.M.B. 01079, \\ Enugu State, Nigeria
}

\begin{abstract}
Problem statement: Resistance to third generation cephalosporins due to acquisition and expression of Extended Spectrum $\beta$-Lactamase (ESBL) among Gram-negative bacteria is on the increase. Infections involving extended spectrum beta lactamase bacteria are associated with significant morbidity and mortality. Therefore, infections due to ESBL isolates continue to pose a serious challenge to infection management worldwide. Since screening for ESBL is not a common practice in hospitals in Enugu state, this study was undertaken to characterize ESBL genes in $K$. pneumoniae strains from intensive care unit of the University of Nigeria Teaching Hospital (UNTH) Enugu. Approach: Over a period of 29 months, 57 patients out of 140 receiving treatment in the intensive care unit of the University of Nigeria Teaching Hospitals Enugu were found to be infected with extended-spectrum $\beta$-lactamase-producing strains of $K$. pneumoniae. Species identification of $K$. pneumoniae strains was performed by Standard Microbiology methods and re-confirmed by MALDITOF technology. Phenotypic characterization of Extended Spectrum Beta Lactamase (ESBL) was determined by double disc synergy test and presence of ESBL genes was determined by specific PCR. Results: All ESBL producers were positive in a PCR for bla $a_{\mathrm{CTX}-\mathrm{M}-1}$ cluster and on sequencing, $b l a_{\mathrm{CTX}}$ M-15 were found to be present. Genotypic characterization of extended spectrum beta-lactamase producing $K$. pneumoniae showed that all isolates carried CTX-M-15and SHV genes, 41(71.9\%)

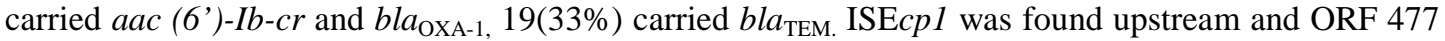
downstream of bla $a_{\text {СтХ-M. }}$ in all strains. Random amplified polymorphic DNA analysis grouped the strains into two clonal groups- A and B and majority of the strains belong to clonal group A $(n=42)$. Conclusion: This study shows for the first time the presence of ESBL genes in K. pneumoniae from the ICU of UNTH Enugu and therefore strongly butresses the need for regular screening for ESBLproducing bacteria in clinical specimen in ICU and other wards in Nigerian hospitals.
\end{abstract}

Key words: Extended Spectrum $\beta$-Lactamase (ESBL), University of Nigeria Teaching Hospital (UNTH), Klebsiella pneumoniae, CTX-M-15, Intensive care unit

\section{INTRODUCTION}

Resistance to oxyimino-cephalosporins such as cefotaxime, ceftriaxone or ceftazidime is a growing problem in the treatment of nosocomial infections and is often caused by the production of Extended Spectrum $\beta$ - Lactamases (ESBLs) (Paterson et al., 2003). ESBLs are frequently identified in $K$. pneumoniae but also in other species such as E. coli, Citrobacter spp.,
Enterobacter spp. and Psuedomonas aeruginosa (Gniadkowski et al., 1998). ESBLs of the CTX-M-type have less than $40 \%$ homology with TEM and SHV (Carton and Coque, 2006). CTX-M- $\beta$-lactamases are rapidly disseminating to different geographical areas including many parts of Europe, Asia, Africa and the Americas (Al-Agamy et al., 2006). Epidemiological reports demonstrate that some enzymes are more frequent than others and the predominant enzyme types

Corresponding Author: Iroha, I.R., Department of Applied Microbiology, Faculty of Biological Sciences, Ebonyi State University, P.M.B. 053, Abakaliki Tel: +2347063302924 
vary with country and the diverse CTX-M-types often exist within a single country (Livermore et al., 2007; Coque et al., 2002). Klebsiella spp. particularly $K$. pneumoniae is an important cause of nosocomial infections and the main population at risk are neonates and immunocompromised hosts. An outbreak of multiple resistant Klebsiella, which causes systemic infections and death has been wildly reported (Podschum and UIImann, 1998). Klebsiella became resistant to broad-spectrum $\beta$-lactam antibiotics due to the emergence and spread of plasmid-mediated $\beta$ lactamases such as Extended Spectrum $\beta$-Lactamases (ESBLs) and has been associated with infection acquired in the Intensive Care Units (ICU) (Tenover and Hughes, 1996). The frequent use of antimicrobial agents in ICUs increases the likelihood of infection with resistant strains (John et al., 1983; Pessoa-Silva et al., 2003). An increasing emergence of multidrug resistance among Klebsiella pneumoniae nosocomial isolates has limited the therapeutic options for the treatment of the intra-hospital infections caused by this opportunistic pathogen. A multidrug resistance phenotype results from the progressive accumulation of different mechanism of resistance in the same microorganism, including high-level production of Extended-Spectrum $\beta$-Lactamases (ESBLs). No data on genotype of ESBL from K. pneumoniae is available in this region of Nigeria. Therefore, this study was undertaken to characterize ESBL genes in $K$. pneumoniae strains from intensive care unit of University of Nigeria Teaching Hospital (UNTH) Enugu.

\section{MATERIALS AND METHODS}

Collection of bacteria strains: Fifty-seven isolates of ESBL producing $K$. pneumoniae were isolated from 140 patients receiving treatment in the ICU of UNTH Enugu over a period of 29 months. ESBL producing $K$. pneumoniae was recovered from urine (39) and sputum (18). These clinical samples were collected from male and female patients within the age range of 9-97 years and were characterized using standard microbiology techniques and re-confirmed by MALDI-TOF (NCCLS, 1997; Laura et al., 2010).

Phenotypic characterization of ESBLs: Extended spectrum beta lactamases were determined by the Double Disc Synergy Test (DDST) method. This was performed by placing disks of ceftazidime, cefotaxime, ceftriaxone, cefepime and aztreonam (30 $\mu \mathrm{g}$ each) at a distance of $15 \mathrm{~mm}$ (center to center) from a disk containing amoxicillin plus clavulanic acid (20 and 10 $\mu \mathrm{g}$ ) respectively (Pitout et al., 2004).

Isolation of genomic DNA: Genomic DNA of the ESBL producing $K$. pneumoniae was prepared using the Nucleospin Kit (Macherey and Nagel, Germany) following manufacturer's instructions.

Detection of ESBL gene by PCR: Genes for TEM, SHV, CTX-M, OXA-1, aac (6')-Ib-cr, ISEcp-1 and ORF 477 beta lactamases was determined by PCR using specific primers as described by (Schleslinger et al., 2005; Karisik et al., 2006; Park et al., 2006; Eckert et al., 2006) with primers shown in Table 1.

Table 1: Primers used in this study

\begin{tabular}{|c|c|c|c|}
\hline Primer & Sequence & Amplicon size & Source \\
\hline TEM-seq & ATAAAATTCTTGA & $860 \mathrm{bp}$ & Yun-Tae et al. (2006). \\
\hline TEM-rev & GACAGTTACCAATGCTTAATC & & \\
\hline \multirow[t]{2}{*}{ SHV-seq } & TCGTTATGCGT & & \\
\hline & TATATTCGCC & $776 \mathrm{bp}$ & Yun-Tae et al. (2006). \\
\hline SHV-rev & GGTTAGCGTTGCCAGTGCT & & \\
\hline \multirow[t]{2}{*}{ CTX-M-seq } & CGCTTTGCG & & \\
\hline & ATGTGCAG & $730 \mathrm{bp}$ & Yun-Tae et al. (2006). \\
\hline CTX-M-rev & ACCGCGATATCGTTGGT & & \\
\hline \multirow[t]{2}{*}{ OXA-1-fw } & GGATAAAACC & & \\
\hline & CCCAAAGGAA & $369 \mathrm{bp}$ & Karisik et al. (2006). \\
\hline OXA-1-rev & TGCACCAGTTTTCCCATACA & & \\
\hline \multirow[t]{2}{*}{ ISEcp 1-5 } & TTCAAAAAGC & & \\
\hline & ATAATCAAAGCC & Variable & Eckert et al. (2006). \\
\hline MA1-rev & ACYTTACTGGTRCTGCACAT & & \\
\hline CTX-M-1-540 & GCGTGATACCACTTCACCTC & $460 \mathrm{bp}$ & This study \\
\hline \multirow[t]{2}{*}{ orf $477-$ rev } & GAAGGAGAACC & & \\
\hline & AGGAACCAC & $482 \mathrm{bp}$ & This study \\
\hline \multirow[t]{2}{*}{ aac6-Ib-fw } & TTGCGATGCTCTA & & \\
\hline & TGAGTGGCTA & & Park et al. (2006). \\
\hline aac6-Ib-rev & CTCGAATGCCTGGCGTGTTT & & \\
\hline RAPD-1290 & GTGGATGCGA & & Appleford and Denman (1979). \\
\hline
\end{tabular}


Amplified PCR products were separated on $0.8 \%$ agarose gels at 100 Volts, stained with ethidium bromide and visualized under UV illumination. Appropriate positive and negative controls were used in all cases.

Randomly Amplified Polymorphic DNA (RAPD) analysis: RAPD was performed with all positive ESBL $K$. pneumoniae strains with a single primer 5'GTGGATGCGA-3' (Appleford and Denman, 1979). Amplified PCR products were separated on $1.5 \%$ agarose gels at 75 Volts.

\section{RESULTS}

As shown in Table $257 \mathrm{~K}$. pneumoniae strains were ESBL positive, 39(68.4\%) were samples from urine and 18(31.6\%) were from sputum. 24(42.2\%) were from male patients while $33(57.8 \%)$ were from female. Greater proportion of ESBL was isolated from patients between the ages of 22-30 years 36(63.1\%). Also all the 57 strains of $K$. pneumoniae gave an amplicon using primers that amplified all currently known CTX-Mgenes. Subsequently a PCR specific for CTX-M-1 cluster gene was performed and was positive in all strains.

Table 2: Demographic AND Patients DATA

\begin{tabular}{lr}
\hline Nos of positive ESBL & 57.00 \\
\hline Nos of female patients & 33.00 \\
Nos of male patients & 24.00 \\
Age range of patients & $9-79$ \\
Patients below 30 years of age & 36.00 \\
Mean age of patients & 27.20 \\
Isolates from Urine & 39.00 \\
Isolates from sputum & 18.00 \\
\hline
\end{tabular}

Table 3: Frequency of occurrence of $\beta$ - lactamase genes

\begin{tabular}{lr}
\hline$\beta$ - lactamase genes & Number positive \\
\hline CTX-M-1 & 57 \\
ISEcp 1 & 57 \\
ORF 477 & 57 \\
SHV & 57 \\
TEM & 30 \\
OXA-1- & 57 \\
aac(6)-Ib-cr & 41 \\
\hline
\end{tabular}

Table 4: Clonal classification of $K$. pneumoniae ESBL

\begin{tabular}{ll}
\hline RAPD Clonal group & K. pneumoniae \\
\hline A & 42 \\
B & 15 \\
\hline
\end{tabular}

Table 5: PCR results in relation to RAPD groups

\begin{tabular}{llr}
\hline PCR tests & Clone A & Clone B \\
\hline CTX-M-1 & 45 & 12 \\
ISE $c p$ 1 & 45 & 12 \\
ORF 477 & 45 & 12 \\
SHV & 45 & 12 \\
TEM & 22 & 8 \\
OXA-1- & 45 & 12 \\
aac(6)-Ib-cr & 50 & 04 \\
\hline
\end{tabular}

PCRs for ISEcpl upstream and ORF 477 downstream were positive in all strains Table 3. PCRs for TEM were positive in 19(33\%) of the isolates while OXA-1- and aac (6') $\mathrm{Ib}$ - $\mathrm{cr} \beta$-lactamase genes were positive in the majority of ESBL isolates 41(71.9\%).

SHV beta lactamases was found to be present in all the strains as expected. RAPD analysis of positive ESBL strains for clonal relatedness grouped our strains into two clonal groups (A and B). Clone A was by far the most frequent clone and found in 42(73.6\%). PCR results in relation to clonal type are presented in Table 4. The association of CTX-M-1 cluster genes to TEM, OXA-1 and aac (6')- $\mathrm{Ib}-\mathrm{cr}$ is stronger in Clone A ESBLs than in other clonal types (Table 5).

\section{DISCUSSION}

In the present study, we characterized strains of $K$. pneumoniae harbouring CTX-M-15 ESBL in the intensive care unit of UNTH in Southeastern, Nigeria where there is no record of investigation of molecular epidemiology of ESBL $K$. pneumoniae. Nosocomial bacterial infections constitute a substantial cause of morbidity and mortality in developing countries such as Nigeria. K. pneumoniae is known to be one of the major organisms causing nosocomial infections within the hospital and has also been implicated in community acquired ESBL. The observation of ESBL producing $K$. pneumoniae strains in this study is very alarming and this could be attributed to the indiscriminate and widespread use of antibiotics, particularly beta lactam antibiotics in this unit of the hospital.

This misuse of antibiotics might have contributed to the emergence of ESBL. Fifty-seven multiple resistant $K$. pneumoniae strains were isolated in the intensive care unit of UNTH Enugu; all strains of $K$. pneumoniae were found to be Producing Extended Spectrum Beta Lactamases (ESBLs), which harbored ESBLs of the CTX-M-1 cluster. These results further emphasize that this enzyme is now one of the most common CTX-M $\beta$-lactamases worldwide. One finding that is worthy of noting in our study is that most ESBL isolates were detected in urine from young patients between the ages of 22-30.

We observed a high association of CTX-M-1 cluster ESBLs with ISEcp 1 upstream and ORF 477 downstream of the gene, with the presence of TEM and OXA-1 beta lactamases and with the detection of aac (6')-Ib-cr. Bla ${ }_{\text {SHV }}$ was found to be present in all the strains as expected.

The presence of ESBL- producing $K$. pneumoniae especially in the ICU of this hospital could lead to 
major therapeutic and epidemiological consequences if not taken care of. Multiple outbreaks of ESBLproducing Enterobacteriaceae have been reported over the past decades and $K$. pneumoniae has been shown to be the most frequently involved organism (Rebuck et al., 2000; Quale et al., 2002). Over the past decades, CTX-M genes have become the most common ESBLs in many countries all over the Europe, Asia, Africa and America (Livermore et al., 2007). Random amplified polymorphic DNA result indicates that majority of the ESBL strains belongs to clonal group A 42(71.9\%) showing that ESBL outbreaks from this unit may be due to a single clone. Evidence for nosocomial transmission of a single strain can be inferred because of the fact that most of the strains belong to one clone. The rapid and massive spread of CTX-M- type of ESBLs is rapidly changing the ESBL epidemiology and in some geographical areas, these enzymes are now the most prevalent ESBLs in Enterobactericeae. Outbreaks of CTX-M- 15- producing Enterobactericeae have also been reported in France, Italy, Spain, Portugal, Austria, Norway, the United Kingdom, Tunisia, South Korea, Canada, Egypt, Nigeria and Kuwait (Al-Agamy et al., 2006; Livermore et al., 2007; Ensor et al., 2009; Conceicao et al., 2005; Soge et al., 2006; Abbassi et al., 2006; Schleslinger et al., 2005). The rate of ESBL expression from our study was quite high compared to other geographical areas of the world. The high rate of ESBLs among hospitalized patients is a global problem as reported in our findings and it is generally thought that patients infected by an ESBL-producing organism are at an increased risk of treatment failure with extended spectrum beta lactam drug. This has posed a very serious problem in this part of Nigeria because alternative antibiotics therapy is difficult to find and as a result patients infected with an ESBL producing organism most often do not survive.

\section{CONCLUSION}

In conclusion, our study revealed for the first time the presence of $K$. pneumoniae producing CTX-M-15 ESBL in the intensive care unit of UNTH, which is an evidence of its increase detection in patients in this unit. More studies on the cefotaxime-resistant Klebsiella sp. and other enterobactericeae need to be carried out in this region of Nigeria not only in the ICU but also in other wards of the hospital.

\section{ACKNOWLEDMENT}

The funding for this study was provided by Swipha Pharmaceutical Company Lagos Nigeria.

\section{REFERENCES}

Abbassi, M.S., C. Torres, W. Achour, L. Vinue and Y. Saenz, 2006. Genetic characterisation of CTX-M15-producing Klebsiella pneumoniae and Escherichia coli strains isolated from stem cell transplant patients in Tunisia. Int. J. Antimicrob. Agents, 32: 308-314. PMID: 18620848

Al-Agamy, M.H.M., M.S.E. Ashour and I. Wiegand 2006. First description of CTX-M $\beta$-lactamaseproducing clinical Escherichia coli isolates from Egypt. Inter. J. Antimicrob. Agents., 27: 545-548.

Carton, R and T.M. Coque, 2006. The CTX-M beta lactamases pandemic. Curr. Opin. Microbiol., 9: 466-475. PMID: 16942899

Coque, T.M., A. Oliver, J.C. Perez-Diaz, F. Baquero and R. Canton, 2002. Genes encoding TEM-4, SHV-2 and CTX-M-10 extended spectrum beta lactamases are carried by multiple Klebsiella pneumoniae clones in a single hospital (Madrie), 1989-2000). Antimicrobio. Agents. Chem., 46: 500-510. DOI: 10.1128/AAC.46.2.500-510

Conceicao, T.A. A. Brizio, L.M. Duarte Lito and J.M. Cristino et al., 2005. First description of CTX-M15-producing Klebsiella pneumoniae in Portugal. Antimicrob. Agents. Chem., 49: 477-478. PMID: 15616344

Yun-Tae, K., K. Tae-Un and B. Hyung-Suk, 2006. Characterization of extended spectrum $\beta$ lactamase genotype TEM, SHV and CTX-M producing Klebsiella pneumoniae isolated from clinical specimens in Korea. J. Microbiol. Biotechnol., 16: 889-95.

Eckert, C., V. Gautier and G. Arlet, 2006. DNA sequence analysis of the genetic environment of various blaCTX-M genes. J. Antimicrob. Chem., 57: 14-23. PMID: 16291869

Ensor, V.M., W. Jamal, V.O Rotimi, J.M. Evanshaduch and P.M. Hawkey, 2009. Predominance of CTX-M-15 extended spectrum beta-lactamases in diverse Escherichia coli and Klebsiella pneumoniae from hospital and community patients in Kuwait. Int. J. Antimicrob. Agents., 33: 487-489. PMID: 19097760

Gniadkowski, M., I. Schnedider, R. Jungwirth, W. Hryniewiez and A. Bauernfeind, 1998. Ceftazidimeresistant enterobacteriaceaeisolates from three polish hospitals: Identification of three novel TEM- and SHV-5-Type extended-spectrum $\beta$-Lactamases. Antimicrob. Agents. Chem., 42: 514-520.

John, J.F. Jr., K.T. McKee Jr, J.A. Twitty and W. Schaffner, 1983. Molecular epidemiology of sequential nursery epidemics caused by multiresistant Klebsiella pneumoniae. J. Pediat., 102: 825-830. PMID: 6343571 
Karisik, E., M.J. Ellington, R. Pike, R.E. Warren and D.M. Livermore et al., 2006. Molecular characterization of plasmids encoding CTX-M-15 $\beta$-lactamases from escherichia coli strains in the United Kingdom. J. Antimicrob. Chem., 58: 665668. DOI: $10.1093 / \mathrm{jac} / \mathrm{dk1} 309$

Livermore, D.M., R. Canton, M. Gniadkowski, P. Nordmann and G.M. Rossolini et al., 2007. CTX-M: Changing the face of ESBLs in Europe. J. Antimicrob. Chem., 59: 165-174. PMID: 17158117

NCCLS, 1997. Performance Standards for Antimicrobial Disk Susceptibility Tests: Approved Standard. 6th Edn., NCCLS, Wayne, Penn, ISBN: 1562383086, pp: 26.

Paterson, D.L., K.M. Hujer, A.M. Huger, B. Yeiser and M.D. Bonomo et al., 2003. Extended-spectrum $\beta$-lactamases in klebsiella pneumoniae bloodstream isolates from seven countries: Dominance and widespread prevalence of SHVand CTX-M-Type $\beta$-lactamases. Antimicrobio. Agents. Chem., 47: 3554-3560. DOI: 10.1128/AAC.47.11.3554-3560.2003

Appleford, D.J and A.M. Denman, 1979. Fate of herpes simplex virus in lymphocytes from inflammatory joint effusions. ii. Mechanisms of non-permissiveness. J. Clin. Microbiol., 38: 450455. PMID: 229778

Park, C.H., A. Robicsek, G.A. Jacoby, D. Sahn and D.C. Hopper, 2006. Prevalence in the United States of aac $\left(6^{\prime}\right)$-Ib-cr encoding a ciprofloxacinmodifying enzyme. Antimicrob. Agents. Chem., 50: 3953-3055. DOI: 10.1128/AAC.00915-06

Pessoa-Silva, C.L., B.M. Moreira, V.C. Almeida, B. Flannery and M.C.A. Lins et al., 2003. Extended spectrum $\beta$-lactamases-producing Klebsiella pneumoniae in a neonatal intensive care unit: Risks factors for infection and colonization. J. Hosp. Infect., 53: 198-206. PMID: 12623321

Laura, F., S. Fernando, G. Magdalena, C. David and H. Ana et al., 2010. Direct identification of urinary tract pathogens from urine samples by matrixassisted laser desorption ionization-time of flight mass spectrometry. J. Clin. Microbiol., 48: 21102115. DOI: 10.1128/JCM.02215-09
Pitout, J.D.D., H. Ashfaque and N.D. Hanson, 2004. Phenotypic and Molecular detection of CTX-M- $\beta$ lactamases produced by Escherichia coli and Klebsiella spp. J. Clin. Microbiol., 42: 5715-5721. DOI: 10.1128/JCM.42.12.5715-5721.2064

Podschum, R. and U. Ullmann, 1998. Klebsiella spp. As nosocomial pathogens: Epidemiology, taxonomy, typing methods and pathogenicity factors. Clin. Microbiol. Rev., 11: 589-603. PMID: 9767057

Quale, J.M., D. Landma, P.A. Bradford, M. Visalli and J. Ravishankar, 2002. Molecular epidemiology of a citywide outbreak of extended-spectrum betalactamase-producing Klebsiella pneumoniae infection. Clin. Infect. Dis., 35: 834-841. PMID: 12228820

Rebuck, J.A., K.M. Olsen, P.D. Fey, A.N. Langnas and M.E. Rupp, 2000. Characterization of an outbreak due to extended spectrum beta lactamase producing Klebsiella pneumoniae in a pediatric intensive care unit transplant population. Clin. Infect. Dis., 31: 1368-1372. PMID: 11096004

Schleslinger, J., S. Navon Venezia, I. Chmelnistsky, O. Hammer-Munz and A. Leavitt et al., 2005. Extended-Spectrum Beta-Lactamases among Enterobacter Isolates Obtained in Tel Aviv, Israel. Antimicrob Agents. Chem., 49: 1150-1156. DOI: 10.1128/AAC.49.3.1150-1156.2005

Soge, O.O., A.M. Queenan, K.K. Ojo, B.A. Adeniyi and M.C. Roberts, 2006. CTX-M-15 extendedspectrum $\beta$-lactamase from Nigerian Klebsiella pneumoniae. J. Antimicrob, Chem., 57: 24-30. DOI: $10.1093 /$ jac/dki429

Tenover, F. and J.M. Hughes, 1996. The challenges of emerging infectious diseases: Development and spread of multiple-resistant bacterial pathogens. J. Am. Med. Ass., 275: 300-304. PMID: 8544270 